\title{
PIPEQ-OS - an instrument for on-site measurements of the experiences of inpatients at psychiatric institutions
}

\author{
Oyvind Bjertnaes*, Hilde Hestad Iversen and Johanne Kjollesdal
}

\begin{abstract}
Background: The Psychiatric Inpatient Patient Experience Questionnaire (PIPEQ) was developed for post-discharge measurements of experiences, but the low response rates associated with post-discharge surveys restrict their usefulness. A new questionnaire was developed based on the PIPEQ for on-site measurements of patient experiences: the PIPEQ-OS. The aim of this study was to psychometrically test the PIPEQ-OS using data from a nationally representative survey conducted in Norway in 2014.
\end{abstract}

Methods: Data were collected using a nationally representative patient-experience survey; $25 \%$ of the institutions in each of the 4 health regions in Norway were randomly selected, yielding a total of 26 institutions. The PIPEQ-OS questionnaire was completed by patients on-site on an agreed day in week 37 of 2014. Item missing and ceiling effects were assessed, and factor analysis was used to assess the structure of the items included in the PIPEQ-OS. The scales were tested for internal consistency reliability, test-retest reliability and construct validity.

Results: The initial sample comprised 857 patients. Of these, 60 were excluded for ethical reasons and 57 were excluded because they were absent on the day of the survey. Of the remaining 740 patients, 552 (74.6\% of the included population) returned the questionnaire. Low levels of missing or "not applicable" responses were found for 18 of the 21 items (<20\%), and 20 of 21 items were below the ceiling-effect criterion. Psychometric testing identified three scales: structure and facilities (six items), patient-centred interaction (six items) and outcomes (five items). All scales met the criterion of 0.7 for Cronbach's alpha (range: $0.79-0.91$ ) and test-retest reliability (range: $0.83-0.84$ ). The construct validity of the scales was supported by 14 of 15 significant associations with variables known to be related to psychiatric inpatient experiences.

Conclusions: The PIPEQ-OS comprises three scales with satisfactory internal consistency reliability and construct validity. This instrument can be used for on-site assessments of psychiatric inpatient patient experiences, but further research is needed to evaluate its usefulness as basis for external quality indicators.

\section{Background}

Patient centredness is an important aspect of the quality of health care; it is a separate component of many health-care quality conceptualizations $[1,2]$ and is often measured by means of surveys of patient-reported experiences. Legislation and policy documents in many Western countries underpin this development, with an increased focus on patient rights and patient centredness. The proven link between patient experiences and clinical safety and effectiveness [3] has provided a clinical

\footnotetext{
* Correspondence: oan@kunnskapssenteret.no

Department for Quality and Patient Safety, The Norwegian Knowledge

Centre for the Health Services, Boks 7004 St Olavs Plass 0130, Oslo, Norway
}

rationale for the focus on improving patient experiences. Numerous research studies and national quality measurement efforts have been conducted relating to patient satisfaction and patient experiences $[4,5]$; however, the psychiatric services have not generally been included in this general literature. For example, psychiatry was excluded from a large systematic review of the measurement of patient satisfaction [4], and was only a minor part of the identified studies in a systematic review of the links between patient experiences and clinical safety and effectiveness [3]. Furthermore, a systematic review of national and cross-national surveys on patient experiences yielded only a few relevant surveys [5]. Thus, the general 
literature appears to offer relatively little insight into the measurement of the experiences of patients using psychiatric services.

Several specific reviews have been published on patient satisfaction with psychiatric services [6-9]. A review by Boyer et al. identified 15 self-report instruments that can be used to measure psychiatric inpatient satisfaction, based on a search of MEDLINE for the years 1988-2008 [9]. The review gave a rather negative view of existing instruments, stressing the lack of standardized definitions and measurement methods, and the inconsistent use of validation procedures [9]. Several instruments have since been published [10-13], but although it is possible that other instruments exist, the review and recently published primary studies point to a need for a standardized definition and measurement methods. This is supported by the conclusion of a general review of patient satisfaction instruments [14].

The Psychiatric Inpatient Patient Experience Questionnaire (PIPEQ) was developed and validated to measure patient experiences post-discharge $[15,16]$. This questionnaire is part of the Norwegian program for the measurement of patient-reported experiences that was set up to provide external indicators at the institution level to support quality improvement, hospital management, free patient choice and public accountability. The PIPEQ was developed as part of the national program, but the very low rate of response to mailed post-discharge surveys of psychiatric inpatients restricts their validity and usefulness. A national survey performed in 2005 had a response rate of $35 \%$ [17], and another survey conducted at a university hospital had a response rate of $23 \%$, even after two postal reminders [18]. In general, although the response rate is a poor indicator of non-response bias [19], the small number of patients per psychiatric institution in Norway renders it almost impossible to compensate for it by increasing the sample size.

The literature documents effective initiatives for increasing the response rate in postal and electronic surveys [20], but some of these have not proven successful when actually applied (e.g. multiple reminders) [18]. Furthermore, reviews of patient-satisfaction studies with psychiatric services have revealed that response rates can be higher in on-site studies than in post-discharge surveys $[7,9]$. This finding was supported by a review of response rates in 210 patient-satisfaction studies, which found higher response rates for face-to-face recruitment than for mail surveys [21]. This has prompted a fundamental change to data collection, from post-discharge to on-site. Naturally, the content of the questionnaire had to be adjusted to the on-site context, and standardized procedures for data collection had to be developed.

The primary aim of this study was to psychometrically test the on-site version of the PIPEQ version (PIPEQ-OS) using data from a nationally representative survey conducted in Norway in 2014. While the study was not designed to assess the effect of on-site versus post-discharge data collection on the response rate, the response rate was clearly an important success criterion for the project.

\section{Methods}

The national survey was conducted by the Norwegian Knowledge Centre for the Health Services (NOKC), commissioned by the Norwegian Directorate of Health, and was formally connected to the national quality indicator system, which meant that the selected institutions were obliged to participate.

\section{Data collection}

The population consisted of adult (age $\geq 18$ years) inpatients receiving specialized mental health care in 2014. Outpatient clinics, day units, age-psychiatric institutions, interdisciplinary treatment institutions for substance dependence and safety departments were excluded. Twenty-five percent of the institutions in each of the 4 health regions in Norway were randomly selected, yielding a total of 26 institutions. The sample comprised all patients staying at one of these institutions on an agreed day in week 37 of 2014.

The NOKC established regional contact persons to help compile the institution lists and to make contact with selected institutions. Two contact persons were established for each participating institution: a projectresponsible professional and a substitute. The contact person at the institution informed staff about the survey, ensured that the institution complied with the recommended survey guidelines, sent out information regarding administrative data, including department overview, and ensured that a day for survey completion was selected. The institution contacts were responsible for establishing a member of staff for each department (the departmental responsible professional) who would be responsible for conducting the survey in that department. Tasks included disseminating information to the patients and employees, distributing and collecting of questionnaires, and reporting to the NOKC regarding the progress of the survey.

Standardized guidelines for data collection were developed. Each patient's clinician was not allowed to be involved in the data collection. The patients were requested to complete the questionnaire by themselves, without discussion or influence from other patients or employees. The department employees were allowed to read to and help the patients to understand the questions, but without influencing the response. The departmental responsible professional distributed a closed envelope containing the questionnaire, an information letter regarding the survey and a reply envelope to the 
patient, and then collected the reply envelope containing the questionnaire when the patient had responded.

\section{Questionnaire}

The PIPEQ-OS was based on the PIPEQ [15], but the question formulations were altered to account for the patients answering them on-site rather than postdischarge. Furthermore, since the PIPEQ was developed more than 10 years ago, it was necessary to update it according to the latest developments of the national program, which included the ten-item Generic Short Patient Experiences Questionnaire [18], a threeitem modified version of the Patient Enablement Instrument (PEI) [22], and a newly developed patient-experience questionnaire for interdisciplinary treatment institutions for substance dependence [23]. The questionnaire was also updated according to the latest developments regarding layout, formatting and structure. The resulting PIPEQ-OS included most of the patient-experience questions from the PIPEQ, with adjustments made to four questions to ensure that it was concordant with the national program. A single item regarding activities was reformulated and supplemented with items regarding activities and facilities from the substance-dependence questionnaire [23], which have been identified in patientbased instruments as being important for psychiatric inpatients $[11,13]$. A single item regarding improvement of mental health was replaced with the three-item modified version of the PEI, which has previously been included and tested in the patient-experience questionnaire for substance dependence [23]. This entire process resulted in the development of the first version of the PIPEQ-OS.

The PIPEQ-OS questionnaire was tested using cognitive interviews among psychiatric inpatients. Ten inpatients from three community mental health centres in one of the health regions in Norway were interviewed. The patients confirmed both the usefulness of responding on-site and the relevance and usefulness of questions on activities and facilities. Some patients reported general problems with reading and responding to the questionnaire, supporting the use of employees to read to and help patients to understand questions where necessary. Some adjustments were made after the interviews, but in general the cognitive interviews showed that the questionnaire functioned well and that the questions and topics were relevant to the patient group.

The revised version of the PIPEQ-OS comprised 41 closed-ended items. Most experience items had a 5 -point response format ranging from 1 ("not at all") to 5 ("to a very large extent"); 21 items related to structures, processes and outcomes at the institution were included in the psychometric testing.

\section{Statistical analysis}

Items were assessed for missing data and ceiling effects, and factor analysis was used to assess the underlying structure of the items. Items with $>20 \%$ missing data were excluded from the factor analysis to avoid extensive loss of responses. Exploratory factor analysis was used to assess the underlying structure of the included items [24]. Principal-axis factoring and extracted factors with eigenvalues above 1 were used. Oblique rotation with Promax was used as a rotation method. Items with low factor loading were considered for removal, and items loading on several factors were placed in the most relevant theoretical factor. Two factor analysis was conducted, one among items of a structural or process character, and one on outcome items. The latter was conducted separately to avoid contamination from the process and structure variables and to test the unidimensionality of the outcome scale. The original authors found that the PEI and satisfaction were related, but were separate constructs [22].

The ceiling effect is defined as the percentage of respondents ticking the most favourable response option, and is an indication of potential problems with measuring changes over time and differences between providers. The criterion relating to the ceiling effect was set to $50 \%[25,26]$.

Items with poor factor loadings were considered for removal from the final solution. The internal consistency reliability of the resulting scales was assessed based on the item-total correlation and Cronbach's alpha values. The former measures the strength of the association between an item and the remainder of its scale, while the latter assesses the overall correlation between items within a scale; a scale is generally considered to be sufficiently reliable when the alpha value is at least 0.7 [27]. The test-retest reliability was assessed by supplying every fourth patient with a retest questionnaire to answer approximately 2 days after completing it the first time. The level of agreement between the two sets of scores was assessed using the intraclass correlation coefficient.

Construct validity is concerned with the extent to which an instrument relates to other variables consistent with theoretically derived hypotheses concerning the constructs that are being measured. Construct validity was assessed through correlations of scale scores and comparisons with responses to five additional questions included within the questionnaire. Correlations between continuous background questions and the scales were assessed by Pearson's $r$, and with $t$-tests for categorical questions. It was hypothesised that the scale scores would be correlated with civil status $[11,17]$ and previous admissions $[11,13]$, the reported experiences and satisfaction are generally worse for single patients and psychiatric patients with previous admissions. Furthermore, it was hypothesised 
that the scores would be associated with the level of coercion related to admission and/or treatment, because patients perceiving coercion report worse experiences and satisfaction [11, 13, 15, 28, 29].

All analyses were performed using SPSS (version 22.0).

\section{Approval}

The national survey was conducted as an anonymous quality assurance project. According to the joint body of the Norwegian Regional Committees for Medical and Health Research Ethics, research approval is not required for quality assurance projects. The Norwegian Social Science Data Services states that anonymous projects are not subject to notification. Patients were informed that participation was voluntary and they were assured of anonymity. Vulnerable patients were protected by allowing the responsible professional at the institution to exclude individual patients for special ethical reasons. Return of the questionnaire represented patient consent, which is the standard procedure in all national patient experience surveys conducted by the NOKC.

\section{Results}

Of the 857 patients who were initially included in the sample, 60 were excluded for ethical reasons and 57 were excluded because they were absent on the day of the survey. The questionnaire was completed and returned by 552 of the remaining 740 patients $(74.6 \%$ of the included population). As indicated in Table 1, $57.6 \%$ of the respondents were female, $41.8 \%$ were in the age range $25-44$ years, $71.7 \%$ were single, $28.2 \%$ had never been admitted before, $26.6 \%$ had a university or college education, and $11.4 \%$ and $28.6 \%$ reported very poor or poor mental health, respectively.

Table 2 indicates that 18 of the 21 items in the PIPEQ-OS instrument had low levels of missing or not applicable responses $(<20 \%)$; exceptions were the items regarding next of kin (36.9\%), medications $(27.0 \%)$ and discharge (25.4\%). Furthermore, 20 of the 21 items were below the $50 \%$ criterion for the ceiling effect, with the exception being the question regarding malpractice (53.6 \%).

Seventeen items were included in the factor analysis. The first factor analysis included 12 items related to structure and process and resulted in 2 factors with an eigenvalue of $>1$ that explained $55 \%$ of the variation: 1 related to structure and facilities and 1 related to patient-centred interactions (Table 3). The second factor analysis included five outcome items and resulted in one factor with eigenvalue of $>1$; this factor explained $74 \%$ of the variation. All scales met the criterion of 0.7 for Cronbach's alpha: the alpha values for structure and facilities, patient-centred interaction and outcome were $0.79,0.86$ and 0.91 , respectively; the corresponding
Table 1 Respondent characteristics $(n=552)$

\begin{tabular}{lll}
\hline & $n$ & $\%$ \\
\hline Gender & & \\
Female & 292 & 57. \\
Male & 215 & 42.4 \\
Age (years) & & \\
$18-24$ & 90 & 17.8 \\
$25-44$ & 212 & 41.8 \\
$45-66$ & 180 & 35.5 \\
$\geq 67$ & 25 & 4.9
\end{tabular}

Marital status

Married

$91 \quad 18.0$

Cohabitating

$52 \quad 10.3$

Single

363

71.7

Education

$\begin{array}{lll}\text { Primary school } & 116 & 23.0\end{array}$

Secondary school $\quad 254 \quad 50.4$

University or college $\quad 134 \quad 26.6$

Previous admissions

0

$143 \quad 28.2$

1

$91 \quad 17.9$

2

3-5

$>5$

25.8

Self-perceived mental health

$\begin{array}{lll}\text { Very poor } & 58 & 11.4 \\ \text { Rather poor } & 145 & 28.6 \\ \text { Both-and } & 160 & 31.6 \\ \text { Rather Good } & 104 & 20.5 \\ \text { Very good } & 40 & 7.9\end{array}$

General condition today

Very poor

Rather poor

$48 \quad 9.5$

Both-and

84

Rather good

Very good

190

16.6

Self-perceived physical health

Excellent

37.6

138

27.3

45

8.9

Very good

5.2

Good

13.7

Rather good

36.2

Poor

27.0

17.9

test-retest reliabilities for these three parameters were $0.84,0.83$ and 0.84 . The construct validity of the scales was supported by 14 of 15 significant associations with variables known to be related to the experiences of 
Table 2 Item descriptions and characteristics

\begin{tabular}{|c|c|c|c|c|c|}
\hline & $n$ & Missing (\%) & Not applicable (\%) & Mean $^{a}$ & Ceiling (\%) \\
\hline Were you welcomed satisfactorily when admitted to the institution? & 525 & 2.5 & 2.4 & 4.04 & 38.1 \\
\hline Have you had enough time for talks and contact with clinicians/personnel? & 478 & 12.1 & 1.3 & 3.63 & 16.5 \\
\hline Do you perceive that the clinicians/personnel understand your situation? & 481 & 12.0 & 0.9 & 3.64 & 22.9 \\
\hline $\begin{array}{l}\text { Have you had the chance to tell the clinicians/personnel what is important about } \\
\text { your condition? }\end{array}$ & 475 & 12.1 & 1.8 & 3.70 & 20.2 \\
\hline $\begin{array}{l}\text { Do you consider that the clinicians/personnel have cooperated well with your } \\
\text { next-of-kin? }\end{array}$ & 348 & 12.1 & 24.8 & 3.19 & 15.5 \\
\hline $\begin{array}{l}\text { Do you consider that the clinicians/personnel have prepared you for the time } \\
\text { after discharge? }\end{array}$ & 412 & 12.9 & 12.5 & 2.75 & 7.3 \\
\hline Do you consider that your treatment has been adjusted to your situation? & 472 & 12.0 & 2.5 & 3.55 & 17.4 \\
\hline Have you had influence on the choice of treatment regime? & 457 & 12.3 & 4.9 & 2.88 & 8.8 \\
\hline Have you had influence on your medication? & 403 & 12.3 & 14.7 & 3.04 & 16.1 \\
\hline Has the institution given you adequate information about your mental condition/diagnosis? & 447 & 12.3 & 6.7 & 3.13 & 12.1 \\
\hline $\begin{array}{l}\text { Has the institution given you adequate information about the treatment options } \\
\text { available to you? }\end{array}$ & 444 & 12.7 & 6.9 & 2.85 & 9.0 \\
\hline Have you felt safe at the institution? & 475 & 12.7 & 1.3 & 4.05 & 37.5 \\
\hline Have the activities offered at the institution been satisfactory? & 457 & 13.2 & 4.0 & 3.59 & 22.8 \\
\hline Have the meals at the institution been satisfactory? & 521 & 4.5 & 1.1 & 3.86 & 28.8 \\
\hline Have you been satisfied with the possibility for privacy? & 515 & 5.4 & 1.3 & 3.77 & 25.6 \\
\hline $\begin{array}{l}\text { Do you believe that you have been subjected to malpractice during your stay } \\
\text { (based on your own opinion)? }\end{array}$ & 513 & 5.1 & 2.0 & 4.12 & 53.6 \\
\hline $\begin{array}{l}\text { Have the help and treatment you have received at the institution improved your } \\
\text { ability to understand your mental condition? }\end{array}$ & 502 & 4.9 & 4.2 & 3.41 & 20.5 \\
\hline $\begin{array}{l}\text { Have the help and treatment you have received at the institution improved your } \\
\text { ability to cope with your mental condition? }\end{array}$ & 505 & 5.1 & 3.4 & 3.24 & 12.1 \\
\hline $\begin{array}{l}\text { Have the help and treatment you have received at the institution led you to believe } \\
\text { that your life will improve after discharge? }\end{array}$ & 504 & 5.3 & 3.4 & 3.30 & 16.1 \\
\hline $\begin{array}{l}\text { All in all, have the help and treatment you have received so far at the institution } \\
\text { been satisfactory? }\end{array}$ & 525 & 4.9 & - & 3.61 & 18.1 \\
\hline $\begin{array}{l}\text { All in all, what benefit have you gained from the treatment you have received so far } \\
\text { at the institution? }\end{array}$ & 514 & 5.1 & 1.8 & 3.33 & 14.0 \\
\hline
\end{tabular}

all items were scored on a 5-point response scale ranging from 1 ("not at all") to 5 ("to a very large degree").

psychiatric inpatients (Table 4). The difference between single patients and those who were married or cohabitating was around 5 points on a scale from 0 to 100 (where 100 is the best score), with singles reporting worse experiences. Previously admitted patients reported worse experiences than patients without a previous admission, but one of three differences was not significant. There were large differences between patients who were admitted voluntarily and involuntarily ( $>10$ points for all scales), with the former group reporting better experiences. Correlations between the scales and two other variables about perceived coercion were also significant and in the same direction as for voluntary versus involuntary admission.

\section{Discussion}

The PIPEQ-OS comprises three scales with satisfactory internal consistency reliability, test-retest reliability and construct validity. Two of these scales concerns patientreported experiences with structures and processes of inpatient care, while the third concerns patient evaluation of outcomes. The instrument was tested in a nationally representative survey in Norway, with a response rate of $74.6 \%$ and low levels of item non-response, thus demonstrating the feasibility and acceptability of on-site data collection.

The PIPEQ-OS is multidimensional and comprised three scales, while the original PIPEQ for post-discharge measurement comprises only one scale $[15,17]$. One reason for this difference was the decision to conduct two separate factor analyses. However, the additional scales were mainly the result of content changes in the questionnaire: outcomes was supplemented with three modified items from the PEI [22], while the on-site context warranted more questions on structure and facilities, since these aspects are important for inpatients [11-13]. The PEI measures a concept different from, but 
Table 3 Factor loadings and reliability statistics

\begin{tabular}{|c|c|c|c|c|}
\hline & Factor loadings $^{a}$ & $\begin{array}{l}\text { Item-total } \\
\text { correlation }\end{array}$ & $\begin{array}{l}\text { Cronbach's } \\
\text { alpha }\end{array}$ & $\begin{array}{l}\text { Test-retest } \\
\text { reliability }\end{array}$ \\
\hline Structure and facilities: & & & 0.79 & 0.84 \\
\hline Were you welcomed satisfactorily when admitted to the institution? & 0.63 & 0.60 & & \\
\hline Have you had enough time for talks and contact with clinicians/personnel? & 0.49 & 0.55 & & \\
\hline Have you felt safe at the institution? & 0.62 & 0.54 & & \\
\hline Have the activities offered at the institution been satisfactory? & 0.46 & 0.55 & & \\
\hline Have the meals at the institution been satisfactory? & 0.72 & 0.46 & & \\
\hline Have you been satisfied with the possibility for privacy? & 0.58 & 0.55 & & \\
\hline Patient-centred interaction: & & & 0.86 & 0.83 \\
\hline Do you perceive that the clinicians/personnel understand your situation? & 0.52 & 0.73 & & \\
\hline $\begin{array}{l}\text { Have you had the chance to tell the clinicians/personnel what is important } \\
\text { about your condition? }\end{array}$ & 0.65 & 0.60 & & \\
\hline Do you consider that your treatment has been adjusted to your situation? & 0.52 & 0.74 & & \\
\hline Have you had influence on the choice of treatment regime? & 0.65 & 0.57 & & \\
\hline $\begin{array}{l}\text { Has the institution given you adequate information about your mental } \\
\text { condition/diagnosis? }\end{array}$ & 0.80 & 0.66 & & \\
\hline $\begin{array}{l}\text { Has the institution given you adequate information about the treatment options } \\
\text { available to you? }\end{array}$ & 0.79 & 0.61 & & \\
\hline Outcomes: & & & 0.91 & 0.84 \\
\hline $\begin{array}{l}\text { Have the help and treatment you have received at the institution improved your } \\
\text { ability to understand your mental condition? }\end{array}$ & 0.79 & 0.75 & & \\
\hline $\begin{array}{l}\text { Have the help and treatment you have received at the institution improved your } \\
\text { ability to cope with your mental condition? }\end{array}$ & 0.88 & 0.83 & & \\
\hline $\begin{array}{l}\text { Have the help and treatment you have received at the institution led you to } \\
\text { believe that your life will improve after discharge? }\end{array}$ & 0.77 & 0.73 & & \\
\hline $\begin{array}{l}\text { All in all, have the help and treatment you have received so far at the institution } \\
\text { been satisfactory? }\end{array}$ & 0.84 & 0.79 & & \\
\hline $\begin{array}{l}\text { All in all, what benefit have you gained from the treatment you have received so } \\
\text { far at the institution? }\end{array}$ & 0.83 & 0.78 & & \\
\hline
\end{tabular}

aseparate factor analysis for outcomes.

Table 4 Construct validity testing: associations between scales and other variables

\begin{tabular}{|c|c|c|c|}
\hline & Structure and facilities & Patient-centred interaction & Outcomes \\
\hline Married or cohabitating & ** & * & * \\
\hline No & 64.7 & 56.5 & 57.6 \\
\hline Yes & 70.0 & 61.4 & 63.6 \\
\hline Previous admissions & * & ns & * \\
\hline No & 69.0 & 59.9 & 63.3 \\
\hline Yes & 65.0 & 57.2 & 57.7 \\
\hline Voluntary admission & $* * *$ & $* * *$ & $* * *$ \\
\hline No & 55.0 & 44.1 & 43.6 \\
\hline Yes & 68.7 & 60.9 & 62.7 \\
\hline Admission perceived as necessary or unnecessary & $0.28^{* *}$ & $0.19^{* *}$ & $0.20^{* *}$ \\
\hline Perception of treatment coercion & $0.44^{* *}$ & $0.42^{* *}$ & $0.49^{* *}$ \\
\hline
\end{tabular}

${ }^{* * *} p<0.001{ }^{* *} p<0.01 ;{ }^{*} p<0.05$; ns, not significant. Pearson's $r$ for continuous variables. 
related to, patient satisfaction [22]. However, the PEI developers correlated the instrument with broad satisfaction instruments that included aspects such as the length of consultation and depth of relationship, which in our terminology relates to structure and process, and not outcomes. It is difficult to compare the dimensionality of the PIPEQ-OS with other inpatient psychiatry instruments since there is considerable variation in the number of dimensions [9-13]. However, the "structure and facilities" scale resembles the term "functional aspects" described in a large systematic review of patient experiences, while the "patient-centred interaction" scale resembles what was referred to elsewhere as "relational aspects" [3]. The PIPEQ-OS does not include questions about adverse effects or patient safety, but might easily be supplemented with validated patient safety instruments if they form part of the study topic (e.g. the Experiences of Therapy Questionnaire) [30].

The PIPEQ-OS is one of many instruments that have been developed for measuring patient evaluation of psychiatric inpatient care. A review of satisfaction instruments published in 2009 identified 15 instruments, but found an absence of a unified measurement approach [9]. Recently published instruments also exhibit a lack of a universal definition and measurement approach [10-13]. Conceptually, three studies claim to have assessed patient satisfaction [10-12], and one measured patient perceptions [13]; however, all of these studies varied regarding item generation methods, subthemes, number of questions and response scales. In fact, only one of these four studies refers to the review from 2009 [11], but the report of that study was co-authored by the first author of the review. Previous reviews also point to the lack of standardization and conceptual models [6-8]. The PIPEQ-OS was developed and validated as part of a long-standing national patientexperience program, consisting of around 15 standardized instruments for measuring patient experiences with different patient groups. This national program uses standardized development and validation methodology, data-collection procedures, type of questions, response scale, and scoring and case-mix system [31-36]. The questionnaire content is heavily based toward patient views. The conceptual approach for the program makes a distinction between patient-reported experiences with non-clinical issues, patient-reported safety and patientreported outcomes, but also allows concurrent measurement of several components [37]. Furthermore, the conceptual approach draws on the work of Donabedian [38], and links patient-reported experiences to structures and processes of care, while patient satisfaction is considered an outcome. The PIPEQ-OS was developed to measure patient experiences on-site - not post- discharge - following data-collection procedures from a national patient-experience survey with substancedependence institutions conducted in 2014 [23]. The three scales were interpreted according to the aforementioned terminology: the structure and facilities scale and the patient-centred interaction scale are conceptually linked to patient-reported experiences, while the outcomes scale is linked to patient-reported outcomes. Thus, the PIPEQ-OS has a clear and broad conceptual base, connecting evaluations from psychiatric patients to the tradition of patient-reported experiences [39], while simultaneously including an outcome scale that combines elements of the traditions of patient-satisfaction measurements [4] and patient-reported outcomes [40-42].

All of the PIPEQ-OS subscales have excellent psychometric properties and are relevant to use as a basis for identifying external quality indicators. However, it is important to note that single items of importance to patients should be retained in the questionnaire, including items regarding next of kin, medications and preparation for discharge, which were excluded following psychometric testing. These topics are important for many patients and are potentially useful for assessing quality improvement. For instance, in a study comparing experiences and importance across ten different patient groups, preparation for discharge was the worst-scoring experience item of all items for inpatient psychiatric patients [18]. Measurement properties are clearly worse for single items than for multi-item scales, but the single items are still an important part of the questionnaire.

More research is needed to evaluate the usefulness of using the PIPEQ-OS as an external quality indicator. This includes correlation studies between the PIPEQ-OS and other quality indicators, analyses that evaluate the discrimination between providers and sensitivity to detect changes over time, and development and testing of case-mix models to use in benchmarking. The predictive validity of the PIPEQ-OS should be studied, and particularly the ability of the outcomes scale to predict compliance and outcomes post-discharge. Qualitative studies to assess local implementation of the data collection protocol should be conducted since local variation might damage comparability. Research on the use of patientexperience data to improve services in this context is important [43], including barriers toward the use of such data, and factors that promote their use [44]. Lastly, the PIPEQ-OS might be cognitively demanding for some patients, and too long for studies with multiple measures. The possibility of obtaining a short version should be assessed in future research.

\section{Limitations}

The PIPEQ-OS is part of a national program whose aim is to provide external indicators at the institution level, 
and to support quality improvement, hospital management, free patient choice and public accountability. While the PIPEQ-OS might function well as a basis for external quality indicators, some limitations should be mentioned. First, the number of responses per institution in this sample is too small to achieve robust quality indicators at the institution level. The choice of surveying all inpatients on a particular day was driven by economic and practical considerations, resulting in few responses and confidence intervals that are too wide to justify confirmation of external indicators at this level. For future national surveys it is recommended that all patients are surveyed within a 4- to 6-month period for each participating institution in order to obtain a sufficient number of responses for constructing external indicators, based on the current size of inpatient institutions in Norway. Second, the one-day approach means that patients are included at different phases of their treatment. While this can be handled with proper adjustment and cautious interpretation, interpretation of all scales might benefit from standardization of timing to the end of the inpatient stay. Data collection close to discharge is also the most common approach in the literature [9]. Third, on-site measurements have been shown to inflate patient evaluation ratings compared to mailed post-discharge surveys $[16,45-48]$, possibly causing problems with discriminating between providers and detecting changes over time. In a Norwegian study involving psychiatric inpatients, the overall on-site score was around 10 points more positive than the post-discharge score on a scale from 0 100 , where 100 is the best [16]. The differences between the national surveys conducted in 2005 (post-discharge) and 2014 (on-site) were typically 5-10 points, depending on the item. Consequently, on-site measurements appear to result in the reporting of experiences that are too positive, implying that comparisons between surveys with different data collection modes should be avoided. However, the PIPEQ-OS produced ceiling effects that were much smaller than those observed in other studies [7]; thus, discriminating between providers and detecting changes over time should not be a major problem. Fourth, the outcome scale measures an intermediate outcome at a single point in time, and is based only on the patient perspective. This scale should be supplemented with other clinical quality indicators and perspectives, and more robust pre-post measurement of patient-reported outcomes. However, the current Norwegian quality indicator system lacks outcome indicators for mental health care. Thus, at the present time the POPEQ-OS has the potential to provide useful information regarding patient-reported outcomes in addition to patient-reported experiences. Lastly, no information was registered about non-respondents and reasons for exclusion based on ethical reasons, causing some uncertainty regarding the generalizability of results.

\section{Conclusions}

The PIPEQ-OS comprises three scales with satisfactory internal consistency reliability and validity. The instrument can be used to assess the experiences of psychiatric inpatients on-site, but further research is needed to evaluate its usefulness as basis for external quality indicators.

\section{Competing interests}

The authors have no competing interests to declare.

\section{Authors' contributions}

OB planned the paper together with $\mathrm{HHI}$ and JK, performed the statistical analysis and drafted the manuscript. $\mathrm{HHI}$ participated in the planning process, critically revised the manuscript draft and approved the final version of the manuscript. JK participated in the planning process, critically revised the manuscript draft and approved the final version of the manuscript. JK was the project manager for the national survey. All authors read and approved the final manuscript.

\section{Acknowledgements}

We thank Inger Opedal Paulsrud for data collection and management, and Linda Selje Sunde for administrative help with the data collection. We are also grateful to the contact persons and project-responsible professionals at the involved departments, institutions and health regions, and the patients for participating in the survey. The national survey was financed by the Norwegian Directorate of Health. The present study was financed by the Norwegian Knowledge Centre for the Health Services.

Received: 26 March 2015 Accepted: 30 September 2015

Published online: 06 October 2015

\section{References}

1. Valentine N, Darby C, Bonsel GJ. Which aspects of non-clinical quality of care are most important? Results from WHO's general population surveys of "health systems responsiveness" in 41 countries. Soc Sci Med. 2008;66(9):1939-50.

2. Arah OA, Westert GP, Hurst J, Klazinga NS. A conceptual framework for the OECD Health Care Quality Indicators Project. Int J Qual Health Care. 2006;18 Suppl 1:5-13.

3. Doyle $C$, Lennox L, Bell D. A systematic review of evidence on the links between patient experience and clinical safety and effectiveness. BMJ Open. 2013;3(1):e001570.

4. Crow R, Gage H, Hampson S, Hart J, Kimber A, Storey L, et al. The measurement of satisfaction with healthcare: implications for practice from a systematic review of the literature. Health Technol Assess. 2002;6(32):1-244.

5. Garratt AM, Solheim E, Danielsen K. National and Cross-National Surveys of Patient Experiences: A Structured Review. In: Rapport: Nasjonalt kunnskapssenter for helsetjenesten. 2008.

6. Ruggeri M. Patients' and relatives' satisfaction with psychiatric services: the state of the art of its measurement. Soc Psychiatry Psychiatr Epidemiol. 1994;29(5):212-27.

7. Lebow JL. Research assessing consumer satisfaction with mental health treatment: a review of findings. Eval Program Plann. 1983;6(3-4):211-36.

8. Powell RA, Holloway F, Lee J, Sitzia J. Satisfaction research and the uncrowned king: challenges and future directions. J Ment Health. 2004;13(1):11-20.

9. Boyer L, Baumstarck-Barrau K, Cano N, Zendjidjian X, Belzeaux R, Limousin S, et al. Assessment of psychiatric inpatient satisfaction: a systematic review of self-reported instruments. Eur Psychiatry. 2009;24(8):540-9.

10. Madan A, Fowler JC, Allen JG, Ellis TE, Hardesty S, Groat M, et al. Assessing and addressing patient satisfaction in a longer-term inpatient psychiatric hospital: preliminary findings on the Menninger Quality of Care measure and methodology. Qual Manag Health Care. 2014;23(3):178-87.

11. Zendjidjian XY, Auquier $P$, Lançon $C$, Loundou $A$, Parola N, Faugère $M$, et al. The SATISPSY-22: Development and validation of a French hospitalized patients' satisfaction questionnaire in psychiatry. Eur Psychiatry. 2015;30(1):172-8.

12. Richardson M, Katsakou C, Torres-González F, Onchev G, Kallert T, Priebe S. Factorial validity and measurement equivalence of the Client Assessment of 
Treatment Scale for psychiatric inpatient care - a study in three European countries. Psychiatry Res. 2011;188(1):156-60.

13. Evans J, Rose D, Flach C, Csipke E, Glossop H, McCrone P, et al. VOICE: developing a new measure of service users' perceptions of inpatient care, using a participatory methodology. J Ment Health. 2012;21 (1):57-71.

14. Sitzia J. How valid and reliable are patient satisfaction data? An analysis of 195 studies. Int J Qual Health Care. 1999;11(4):319-28.

15. Garratt A, Danielsen K, Bjertnaes $\varnothing A$, Ruud T. PIPEQ-a method for measurement of user satisfaction in mental health services. Tidsskr Nor Laegeforen. 2006;126(11):1478-80.

16. Bjertnaes $\varnothing \mathrm{A}$, Garratt A, Johannessen JO. Data collection methods and results in user surveys in mental health care. Tidsskr Nor Laegeforen. 2006;126(11):1481-3.

17. Dahle KA, Holmboe O, Helgeland J. Brukererfaringer med døgnenheter i psykisk helsevern - Resultater og vurderinger etter en nasjonal undersøkelse i 2005. In: Rapport: Nasjonalt kunnskapssenter for helsetjenesten. 2006.

18. Sjetne IS, Bjertnaes OA, Olsen RV, Iversen HH, Bukholm G. The Generic Short Patient Experiences Questionnaire (GS-PEQ): identification of core items from a survey in Norway. BMC Health Serv Res. 2011;11:88.

19. Groves RM. Nonresponse rates and nonresponse bias in household surveys. Public Opin Q. 2006;70(5):646-75.

20. Edwards PJ, Roberts I, Clarke MJ, Diguiseppi C, Wentz R, Kwan I, et al. Methods to increase response to postal and electronic questionnaires. Cochrane Database Syst Rev. 2009;3:MR000008.

21. Sitzia J, Wood N. Response rate in patient satisfaction research: an analysis of 210 published studies. Int I Qual Health Care. 1998;10(4):311-7.

22. Howie JG, Heaney DJ, Maxwell M, Walker JJ. A comparison of a Patient Enablement Instrument (PEI) against two established satisfaction scales as an outcome measure of primary care consultations. Fam Pract. 1998;15(2):165-71.

23. Haugum $\mathrm{M}$, Iversen $\mathrm{HH}$. Pasienterfaringer med døgnopphold innen tverrfaglig spesialisert rusbehandling - resultater etter en nasjonal undersøkelse i 2014. In: Rapport: Nasjonalt kunnskapssenter for helsetjenesten. 2014.

24. Hamilton LC. Regression With Graphics: A Second Course in Applied Statistics. In: Pacific Grove, Calif:. Brooks/Cole. 1992.

25. Bjertnaes OA, Lyngstad I, Malterud K, Garratt A. The Norwegian EUROPEP questionnaire for patient evaluation of general practice: data quality, reliability and construct validity. Fam Pract. 2011;28(3):342-9.

26. Ruiz MA, Pardo A, Rejas J, Soto J, Villasante F, Aranguren JL. Development and validation of the "Treatment Satisfaction with Medicines Questionnaire" (SATMED-Q). Value Health. 2008;1 1(5):913-26.

27. Nunnally JC, Bernstein IH. Psychometric Theory. 3rd edn. McGraw-Hill Series in Psychology. New York: McGraw-Hill; 1994.

28. Smith D, Roche E, O'Loughlin K, Brennan D, Madigan K, Lyne J, et al. Satisfaction with services following voluntary and involuntary admission. J Ment Health. 2014;23(1):38-45.

29. Katsakou C, Bowers L, Amos T, Morriss R, Rose D, Wykes T, et al. Coercion and treatment satisfaction among involuntary patients. Psychiatr Serv. 2010;61(3):286-92.

30. Parker G, Paterson A, Fletcher K, McClure G, Berk M. Construct validity of the Experiences of Therapy Questionnaire (ETQ). BMC Psychiatry. 2014;14:369.

31. Bjertnaes OA, Sjetne IS, Iversen HH. Overall patient satisfaction with hospitals: effects of patient-reported experiences and fulfilment of expectations. BMJ Qual Saf. 2012;21(1):39-46.

32. Bjertnaes $\mathrm{OA}$. The association between survey timing and patient-reported experiences with hospitals: results of a national postal survey. BMC Med Res Methodol. 2012;12:13.

33. Bjertnaes O. Patient-reported experiences with hospitals: comparison of proxy and patient scores using propensity-score matching. Int J Qual Health Care. 2014;26(1):34-40.

34. Garratt AM, Helgeland J, Gulbrandsen P. Five-point scales outperform 10-point scales in a randomized comparison of item scaling for the Patient Experiences Questionnaire. J Clin Epidemiol. 2011;64(2):200-7.

35. Iversen HH, Holmboe O, Bjertnaes OA. The Cancer Patient Experiences Questionnaire (CPEQ): reliability and construct validity following a national survey to assess hospital cancer care from the patient perspective. BMJ Open. 2012;2:5.

36. Garratt AM, Bjertnaes OA, Holmboe O, Hanssen-Bauer K. Parent experiences questionnaire for outpatient child and adolescent mental health services
(PEQ-CAMHS Outpatients): reliability and validity following a national survey. Child Adolesc Psychiatry Ment Health. 2011;5:18.

37. Bjertnaes O, Skudal KE, Iversen HH, Lindahl AK. The Patient-Reported Incident in Hospital Instrument (PRIH-l): assessments of data quality, test-retest reliability and hospital-level reliability. BMJ Qual Saf. 2013;22(9):743-51

38. Donabedian A. The quality of care. How can it be assessed? 1988. Arch Pathol Lab Med. 1997;121(11):1145-50.

39. Gerteis M, Edgman-Levitan S, Daley J, Delbanco TL. Through the Patient's Eyes: Understanding and Promoting Patient-Centered Care. 1st edn. The Jossey-Bass Health Series. San Francisco: Jossey-Bass; 1993.

40. Fitzpatrick R, Davey C, Buxton MJ, Jones DR. Evaluating patient-based outcome measures for use in clinical trials. Health Technol Assess. 1998;2(14). i-iv, 1-74.

41. Hayhurst KP, Massie JA, Dunn G, Lewis SW, Drake RJ. Validity of subjective versus objective quality of life assessment in people with schizophrenia. BMC Psychiatry. 2014;14:365.

42. Baiano M, Salvo P, Righetti P, Cereser L, Baldissera E, Camponogara I, et al. Exploring health-related quality of life in eating disorders by a crosssectional study and a comprehensive review. BMC Psychiatry. 2014;14:165.

43. Haugum M, Danielsen $\mathrm{K}$, Iversen $\mathrm{HH}$, Bjertnaes $\mathrm{O}$. The use of data from national and other large-scale user experience surveys in local quality work: a systematic review. Int J Qual Health Care. 2014;6(6):592-605.

44. Davies E, Cleary PD. Hearing the patient's voice? Factors affecting the use of patient survey data in quality improvement. Qual Saf Health Care. 2005;14(6):428-32.

45. Anastario MP, Rodriguez HP, Gallagher PM, Cleary PD, Shaller D, Rogers WH, et al. A randomized trial comparing mail versus in-office distribution of the CAHPS Clinician and Group Survey. Health Serv Res. 2010;45(5 Pt 1):1345-59.

46. Burroughs TE, Waterman BM, Gilin D, Adams D, McCollegan J, Cira J. Do on-site patient satisfaction surveys bias results? Jt Comm J Qual Patient Saf. 2005;31(3):158-66.

47. Gribble RK, Haupt C. Quantitative and qualitative differences between handout and mailed patient satisfaction surveys. Med Care. 2005;43(3):276-81.

48. Lin OS, Schembre DB, Ayub K, Gluck M, McCormick SE, Patterson DJ, et al. Patient satisfaction scores for endoscopic procedures: impact of a survey-collection method. Gastrointest Endosc. 2007;65(6):775-81.

\section{Submit your next manuscript to BioMed Central and take full advantage of:}

- Convenient online submission

- Thorough peer review

- No space constraints or color figure charges

- Immediate publication on acceptance

- Inclusion in PubMed, CAS, Scopus and Google Scholar

- Research which is freely available for redistribution 